\title{
A Study on the Supply of Medical-Nursing Combined Community Service in China
}

\author{
yang Yang \\ Southwest Jiaotong University, Chengdu,China
}

1141557495@qq.com

Keywords: Community support, Medical-nursing combination, Service supply

\begin{abstract}
This paper studies the supply services of medical-nursing combined community support mode in China through literature review. It is found that the supply service of medical-nursing combined community support mode in China is relatively simple and lacks the service requirement evaluation system, family doctor and elderly contract rate is low. Based on this, three suggestions are put forward to promote the further development of community's medical-nursing combination, to increase the service supply subject, to construct a perfect service demand assessment system and to strengthen the construction of medical staff.
\end{abstract}

\section{Introduction}

With the development of economy and society, human life expectancy has been continuously improved, as of the end of 2015, China's elderly over 60 years old has reached 220 million, about $16 \%$ of the total population. It is predicted that by 2050, the total number of elderly people in China will reach 437 million, accounting for $31.2 \%$ of the total population, the degree of population aging is increasing. In particular, with the deepening of urbanization, a large number of population migration led to the increase in the size of empty-nesters, at the same time, the number of elderly, semi-disabled and chronically ill people has continued to rise. The arrival of the wave of silver has led to rapid growth in demand for medical care and nurse, and the separation of traditional medical and sanitation services has not been able to meet the needs of the elderly. In order to alleviate this contradiction, on September 13, 2013, the state officially issued the "State Council on accelerating the development of pension services, a number of opinions" (Guo Fa [2013] 35), clearly "actively promote medical care and pension services Combined with "into the future development of pension services six major tasks. "Medical-nursing combination " mainly refers to the combination of medical services and pension services. "Medicine" mainly includes medical treatment, disease prevention services, rehabilitation care, hospice care services; "Support" mainly includes daily life care services, mental and psychological services and cultural activities, etc. Medical-nursing combined community support mode is a pension model that to adhere to the dominant position of the government to the community as a platform to give full play to health care institutions, pension agencies, community pension and medical resources to meet the needs of the elderly pension services[1]. At present, China's pension pattern is "9073" model, 90\% of the elderly home care, 7\% of the elderly in the community pension, $3 \%$ of the elderly in the agency pension. Which the family pension to rely on the community. Therefore, the community's medical-nursing combination with the object not only includes the community of all kinds of pension agency of the elderly but also include the elderly at home, the smooth development of community's medical-nursing combination is essential.

Through the literature, most scholars have studied the necessity and development of medical-nursing combined community, it also mentions that in the process of community's medical-nursing combination, the community provides services for the elderly that are not targeted to meet the needs of the elderly, but the study of this problem is not enough depth. To provide a healthy old-age environment for the elderly, a variety of services is essential, the service content is also the core of medical-nursing combined community services, which directly affect the sustainability and the effect of the services[2]. If this problem can not be solved, it will lead to the 
elderly can not get the necessary services, then the pension system will not be perfect. Therefore, this paper studies the problems of imperfect services in medical-nursing combined community in China and puts forward some suggestions to further enrich the connotation of medical-nursing combined community in China.

\section{The current situation of the supply service of medical-nursing combined community in China}

In order to alleviate the increasingly serious aging phenomenon in China, most cities have begun to explore the medical-nursing combined community service model based on their own conditions and requirements. In the process of exploring the medical-nursing combined community pension model, the main body that can provide medical care for the elderly is the community health service center, the hospital, the rehabilitation and recuperation institutions, etc, there have been three kinds of medical-nursing combined community service model nowadays: the first is to set up a medical point, this service model funded by the community, so that the community hospital in the community pension agencies set up medical points, the service object is self-care of the elderly, community medical institutions regularly assigned doctors to provide more common for the elderly of the treatment and health counseling. But this service is still regard the professional daily care as the main service content, and equipped with a simple medical diagnosis. This kind of old-age service model of medical level and quality is very limited, it can not provide disease prevention, treatment, hospice care and other services for the elderly. The second is the medical union, this community pension model is led by one third-grade class-A hospital or more third-grade class-A hospitals, and grass-roots medical institutions to form a consortium, and in collaboration with primary health care institutions to form a consortium. The general practice of this old-age model is to set up a medical point in the community's pension agencies to achieve hierarchical treatment and two-way referral, regard all the elderly who needs for medical services as a client. But this kind of pension service model is more inclined to provide the elderly with the treatment and prevention of chronic diseases, but it is not enough for the elderly to provide services such as psychological counselling and health literacy[3]. The third is to sign a family doctor, which is a team that components of general practitioners, psychologists, nurses and other people in the community health service center, Family doctors have signed up to elderly people, and then provide basic health management and medical counseling services for the elderly, the main service for this pattern is the majority of the community's elderly[4].

In the medical-nursing combined community with the old-age services, The primary providers of the community's pension service are mainly families, nursing homes, and day care centers, the day care center is mainly for the disabled, half disabled elderly services[5]. Community pension institutions pay more attention to the prevention and treatment of chronic elderly people, but it is not enough for the elderly to provide counselling, health literacy and other services. In addition, because the individual pension agencies do not pay attention to the quality of service, serious damage to the reputation of the pension agencies, the elderly and their families also have low recognition of the pension agencies[6]. Communities in some parts of China have begun offering family doctors contracts and door-to-door services for the elderly, but few people are asking for it, and few have signed up.

From the perspective of medical-nursing combined community services as a whole, China is still lack a evaluate system which can evaluate the health status and actual needs of the elderly ,this leads to the inability of medical institutions and pension institutions to provide timely and targeted services to the elderly.

\section{The Problems of the supply service of medical-nursing combined community in China}

Service content is relatively simple. With the increase in the age of the elderly, their social interactions become less and less, and they will become lonely, depressed and depressed in the long run. In China's community home care services, some community pension agencies are usually in 
order to save costs to provide a single service content, mainly to provide a simple life care services, Mainly for the elderly to provide clothing, food, shelter, line of services, has not attached importance to the elderly healthy lifestyle and happy mood and other psychological problems[7]. Not to mention professional health care services for the elderly, including disease prevention, rehabilitation , care and hospice care. The reasons for this problem are that community construction is still lagging behind, and the public services provided by the community for the elderly cannot meet the needs of the elderly [8].

Lack of a system for assessing the needs of pension services. At present in China, whether it is medical institutions or the elderly, they are generally concerned about the disease and not pay attention to health problems, Most of the elderly in the community are waiting until the body is seriously ill, they will go to the hospital to see a doctor, most of them will be diagnosed as a major disease or a serious illness once they see the doctor. This requires professional personnel to give timely intervention and prevention for elderly before they get sick. There is also a lack of a system of comprehensive assessment of the elderly in China[9], which leads to the inability to know whether the elderly have a need for a combination of health care services, there is no way for the elderly to provide the actual situation of targeted and standardized services.

Family doctor and elderly contract rate is low. On June 6, 2016, the national Health Commission issued a "notice on the issuance of guidance to promote the signing of family doctors". The goal is that by 2017, more than 30 percent of family doctors will be signed up for service coverage, and more than 60 percent of key people will be signed up for service coverage. By 2020, the system will be fully covered by the family doctor's contract. Although China has introduced policies that strongly support family doctors to sign up for work, but the implementation of our country is less than ideal[10]. For one thing, the number of medical professionals in China is small, and the majority of medical professionals are not professional. The elderly do not trust the family doctor, the recognition of the family doctor is not high, most sick elderly people generally do not consult the family doctor, if suffering from a minor illness directly to the nearby pharmacy to buy medicine, suffering from serious illness directly to high professional hospital for medical treatment. For another thing, the family doctors don't recognize their work and feel unfulfilled. The general practitioner, who has a heavy daily routine, has no time and experience to sign up for a contract.

\section{Suggestions}

Increase the main body of service supply, and enhance the diversification of service content. Diverse service content is essential for the healthy retirement of older people. There are some special services that we need to provide for medical-nursing combined community, such as rehabilitation services, sick old man after a series of treatment, you can return to the community to accept rehabilitation care, so that both can reduce the economic burden of the elderly, but also can ease the hospital "press bed" phenomenon. Also provide psychological counselling services, not only concerned about the lives of the elderly, but also pay attention to their psychological aspect, discover the psychological problem in time to carry out the guidance. To achieve the purpose of providing a variety of services, you need to increase the supply of service .First of all, the government should increase input to build cultural and recreational facilities for the elderly and provide the necessary old-age resources. Second, improve the supply main body's enthusiasm, encourage private capital or other institutions to participate in community medical combination of pension services, to provide diversified service content, so as to meet the diversified pension service demand in different types of people.

To build a comprehensive assessment system for the needs of pension services to enhance the relevance of services. To realize the health of the elderly requires a comprehensive assessment system. The function of the assessment system is to conduct a comprehensive assessment of the physical condition of the elderly, this will not only early detection of health problems in order to take preventive measures in time, but also to promote timely provision of medical staff with targeted treatment programs. Without a scientific evaluation system, older people will not be able to get targeted medical and pension services in time. First, under the auspices of the government, the 
experts developed the assessment tool, and then the pension agencies used the assessment tool to conduct a regular and comprehensive assessment of the elderly, then the multidisciplinary team analyzed the results of the elderly to identify potential problems and further clarify the etiology of the elderly, and within a certain amount of time, a targeted care plan is developed to ensure that the health and function of the elderly can be maintained at a maximum level. And nursing staff shall be carried out in accordance with the nursing plan implementation and the results of the assessment are communicated to the families of the elderly, early intervention, rule out the risk factors of affect the elderly health. In the end, the changes in the elderly were assessed again, and the care plan was revised to ensure that the physical and psychological aspects of the elderly were met. The service demand assessment system can provide a reasonable demand stratification for the elderly population, and provide the corresponding scientific pension services according to the different old-age service needs of the elderly at all levels.

Strengthen the construction of family doctors team, and promote the sustainable development of pension services. For a long time, most of the elderly think one third-grade class-A hospital cure ability is strong, to a large hospital to see a doctor can be protected, because of the large hospital hardware equipment is perfect, the doctor's professional level. Even if the medical staff of the one third-grade class-A hospital have a bad attitude and long registration, the sick old people will go to the one third-grade class-A hospital. Health care professionals with a high level of professional skills will help improve the acceptance and satisfaction of elderly care services and ensure the sustainability of services. Therefore, in order to improve the recognition and service efficiency of family doctors, we need to strengthen the training of medical staff in China. On the one hand, we should strengthen the training of the team of family doctors, improve the training system for the promotion of talents, and gradually acquire the recognition of the elderly, so as to contract with the family doctors team according to their own needs. Once you're uncomfortable, immediately contact the family doctor and make your the first diagnosis to the community, improve the utilization of medical resources. Second, the government should improve the incentive mechanism, to solve the problem of high-quality talent treatment, refining performance evaluation standard, and they will offer preferential subsidies to professionals in terms of working conditions, housing improvement, etc. It is also important to strengthen the spirit of the talent in order to enhance the enthusiasm of the family doctor service, such as carry out regular models and other activities.

\section{Conclusion}

Aging increasingly serious today, the development of " medical-nursing combined community " support model is an inevitable trend, in the Chinese community, "the medical-nursing combination " is still being explored. However, there are still some problems in the supply services of the medical-nursing combined community in China, for example, the service content is relatively simple, lacks the needs assessment system for the pension service of the aged, and the construction of the medical service personnel needs to be improved. In addition, there are a lot of deficiencies in" the medical-nursing combination " pension model in China, and we need to explore in more aspects. 


\section{References}

[1]Y.E.Li,L.W.Zhao. A Study on medical-nursing combined community support mode from the Perspective of Public and Private Partnership - A Case Study of Meilinyuan Community in Liaoyang City [J]. Aging Scientific Research,2016,(04):64-71. (in chinese)

[2]C.F.Tong,S.S.Wang. Medical-nursing combined community: Value, Practice and Construction Path [J]. Administration and Law,2017,(02):40-46. （in chinese )

[3][9] R.L.Li,X.B.Ye. Construction of medical-nursing combined community support model [J]. Administration and Law,2016,(04):42-47. (in chinese)

[4]X.P.Hu,Y.S.Chen,F.L.Zhao,C.Zhou and F.L.Meng. Discussion on Improving the Effect of Integrating Contract Service with Medical Maintenance [J]. Journal of Community Medicine,2015,(23):69-71. (in chinese)

[5]A.G.Gu. Talking about the Development Path of medical-nursing combination from the Present Situation of Medical Institutions and Pension Institutions [J]. Business Economics Research,(06):112-114. (in chinese)

[6]N.Yan. The Choice of Old - age Pattern of Hollow Nest in the Process of Urbanization: medical-nursing combined community of Urban [J]. Journal of Huazhong Agricultural University (Social Science Edition),2015,(04):22-28. (in chinese )

[7]J.H.Huang,F.Meng.The Necessity, Dilemma and Countermeasure of the Mode of " medical-nursing combination "[J]. Research on China 's Health Policy,2014,(06):63-68. (in chinese ) [8]Q.X.Cheng,Z.Y.Feng,J.Feng,Y.Wang,Y.Huang ang X.J.Chen. The Necessity, Feasibility, Dilemma and Suggestions of Developing medical-nursing combined community in China [J]. China health administration,2016,(05):334-336+380. (in chinese)

[10]Q.Dong,Z.M.Yuan and Q.Guo. The discussion of the integrated intelligent medical service model of medical care [J]. Health Economics Research,2015,(07):51-53. （in chinese ) 